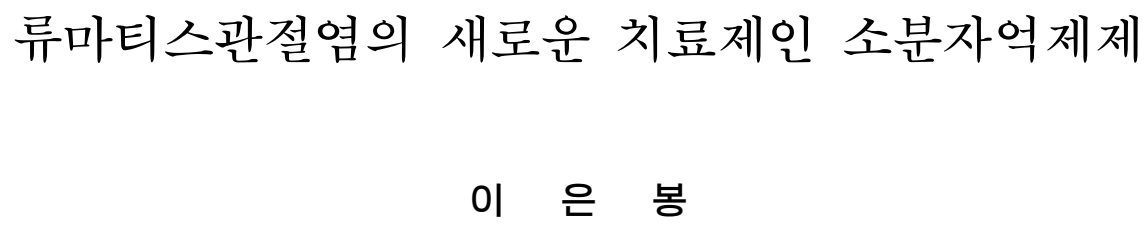

서울대학교 의과대학 내과학교실

\title{
Small Molecule Inhibitors in Rheumatoid Arthritis
}

Eun Bong Lee

Department of Internal Medicine, Seoul National University College of Medicine, Seoul, Korea

Rheumatoid arthritis (RA) is a chronic systemic inflammatory disease predominantly affecting diarthroidal joints. Following the successful application of biologic agents, several small molecule inhibitors are currently under clinical trials. Small molecule inhibitors have several strengths compared with biologics. First, they can target several inflammatory cytokines together by blocking common signal transduction pathways. Second, they can be taken orally. Third, the price can be made flexible. Among the several small molecule inhibitors in the development process, fostamatinib and tofacitinib are the closest to the clinics at the moment. Fostamatinib, which is a Syk inhibitor, showed superior efficacy over placebo with tolerable safety signals. Diarrhea, hypertension and infection

\section{서 론}

류마티스관절염은 주로 활막 관절을 침범하는 원인불명 의 만성 전신 염증성 질환이다. 류마티스관절염의 원인은 아직 정확히 알려져 있지 않지만, 최근의 연구결과에 의하 면 서로 다른 종류의 다양한 염증성 사이토카인들이 발병 에 중요한 역할을 하는 것으로 알려졌다 (1). 최근 TNF- $\alpha$ 를 표적으로 하는 항 TNF- $\alpha$ 제제(Etanercept, Infliximab, Adalimumab, Golimumab, Certolizumab), IL-6를 표적으로 are representative adverse events. Tofacitinib, which is JAK inhibitor, is now finishing phase 3 clinical trials. It showed clinical efficacy comparable to Adalimumab and similar adverse effect profiles to the biologics, which include opportunistic infections. For laboratory abnormalities, leukopenia, anemia, increase of LDL and serum $\mathrm{Cr}$ were reported, which, however, were stabilized with prolonged use. Other classes of small molecule inhibitors did not show impressive efficacy as these small molecule inhibitors. In conclusion, small molecule inhibitors are promising novel therapeutic agents for the treatment of RA. They will be able to change the treatment paradigm of RA if they can show long-term safety.

Key Words. Rheumatoid arthritis, Small molecule inhibitor

하는 항 IL-6 수용체 항체(tocilizumab) 등 생물학적 치료제 의 성공적인 도입은 류마티스관절염의 새로운 치료전략을 제시해 주고 있다 (2-7).

하지만 류마티스관절염 치료에 있어서 최근의 급속한 발 전에도 불구하고, 류마티스관절염의 완치라는 목표는 여 전히 요원한 과제로 남아 있다. 가장 효과적인 생물학적 제제라고 하여도 ACR20에 도달하는 비율이 $60 \%$ 내외에 머물고 있으며, ACR50, ACR70는 각각 $40 \%, 20 \%$ 에 머물

<Received: June 7, 2012, Revised : June 11, 2012, Accepted : June 12, 2012>

Corresponding to: Eun Bong Lee, Department of Internal Medicine, Seoul National University College of Medicine, 101, Daehak-ro, Jongro-gu, Seoul 110-744, Korea. E-mail : leb7616@snu.ac.kr 
고 있다. 효과의 한계뿐만 아니라 부작용 또한 문제점으로 지적되고 있다. 생물학적 제제는 뛰어난 치료 효과에도 불 구하고, 각종 기회감염의 증가 및 일부 암종의 증가가 문 제되고 있다. 또한 모든 제제가 주사 형태로 되어 있어서 투여의 불편을 초래하며, 생물학적 제제의 특성상 제조단 가가 높을 수 밖에 없어서 비싼 약제 가격이 제한점으로 지적되고 있다.

기존 치료제들의 한계로 인하여 류마티스관절염 치료에 있어서 새로운 접근이 시도되고 있다. $\mathrm{B}$ 세포를 표적으로 하는 치료로서 Rituximab이 도입되었고, $\mathrm{T}$ 세포를 표적으 로 하는 치료제로서는 Abatacept가 도입되었다. 하지만 이 들 신약 역시 생물학적 제제라는 한계는 근본적으로 뛰어 넘지 못하고 있다. 또 다른 새로운 시도가 소분자억제제 (small molecule inhibitors)이다. 소분자억제제는 류마티스 관절염의 발생기전에 기반해서 표적 분자를 정한다는 점 에서는, 생물학적 제제와 유사하나, 항체가 아닌 화합물 형태로 제조된다는 점에서 생물학적 제제의 여러 한계를 극복해 줄 수 있을 것으로 기대되는 약물들이다 $(8,9)$. 소분자억제제는 항체 제제에 비하여 여러 측면에서 유리 할 것으로 기대되고 있다. 첫째, 주로 신호전달 체계의 물 질들을 차단함으로써, 다양한 염증성 물질들을 동시에 차 단할 수 있다. 류마티스관절염의 발생에는 다양한 종류의 세포와 사이토카인들이 관여하는 것으로 알려져 있어서, 류마티스관절염의 근치를 위해서는 여러 물질을 동시에 차단할 필요가 있기 때문에 약제의 기전학적 측면에서 이 는 매우 유리한 요소이다. 둘째, 항체 제제에 비해서 반감 기가 매우 짧다. 항체 제제는 반감기가 상대적으로 길어서 최대 6개월에 1회만 투여해도 되는 제제까지 나와 있지만 부작용 측면에서는 반감기가 짧은 것이 오히려 유리할 수 있다. 셋째, 화합물로 경구투여가 가능하다. 항체 제제는
비경구 투여만이 가능하나 소분자억제제는 경구투여가 가 능해서 투여편리성 측면에서 매우 유리하다. 넷째, 화합물 로 제조 단가를 충분히 낮출 수 있다. 항체 제제는 생산단 가를 어느 정도 이하로 낮추는 것이 근본적으로 불가능하 지만, 화합물의 경우는 제조단가의 절약이 상대적으로 수 월하다.

본 논고에서는 최근 도입이 시도되고 있는 다양한 소분 자억제제의 작용기전과 연구 결과를 Fostamatinib과 tofacitinib을 중심으로 살펴보고 향후 전망 등에 대해서 정리보 고자 한다.

\section{류마티스관절염의 발병기전과 소분자억제제}

류마티스관절염의 정확한 발병기전은 아직 알려져 있지 않지만 현재까지의 연구결과에 따르면 다양한 면역세포가 관여하며 특히 CD4+ T 림프구가 발병과정에서 가장 중요 한 역할을 할 것으로 기대되고 있다. 미지의 항원이 shared epitope을 지니는 항원제공세포에 의해서 $\mathrm{CD} 4+\mathrm{T}$ 림프구 에 제공되면, CD4+ T 림프구는 주로 Th1, Th17 세포로 분 화하며, 림프구와 관절내 대식구, 활막세포를 활성화 시킨 다. 활성화된 B 림프구는 류마티스 인자와 같은 자가항체 를 생산하여, 관절염의 악화에 기여하며, 활성화된 대식구 는 IL-1, IL-6, TNF- $\alpha$ 와 같은 염증성 사이토카인을 생산하 여, 관절 내 염증을 유발한다 활성화된 활막세포는 파누스 (pannus)를 형성하며 관절 파괴를 일으키며, 활성화된 파 골세포(osteoclast)는 이 과정에서 중요한 역할을 한다 (10). 생물학적 제제들은 류마티스관절염을 일으키는 각각의 사 이토카인들을 개별적으로 차단하는데 반해서 소분자억제 제는 염증성 사이토카인들을 동시 다발적으로 차단할 수 있다(Figure 1).

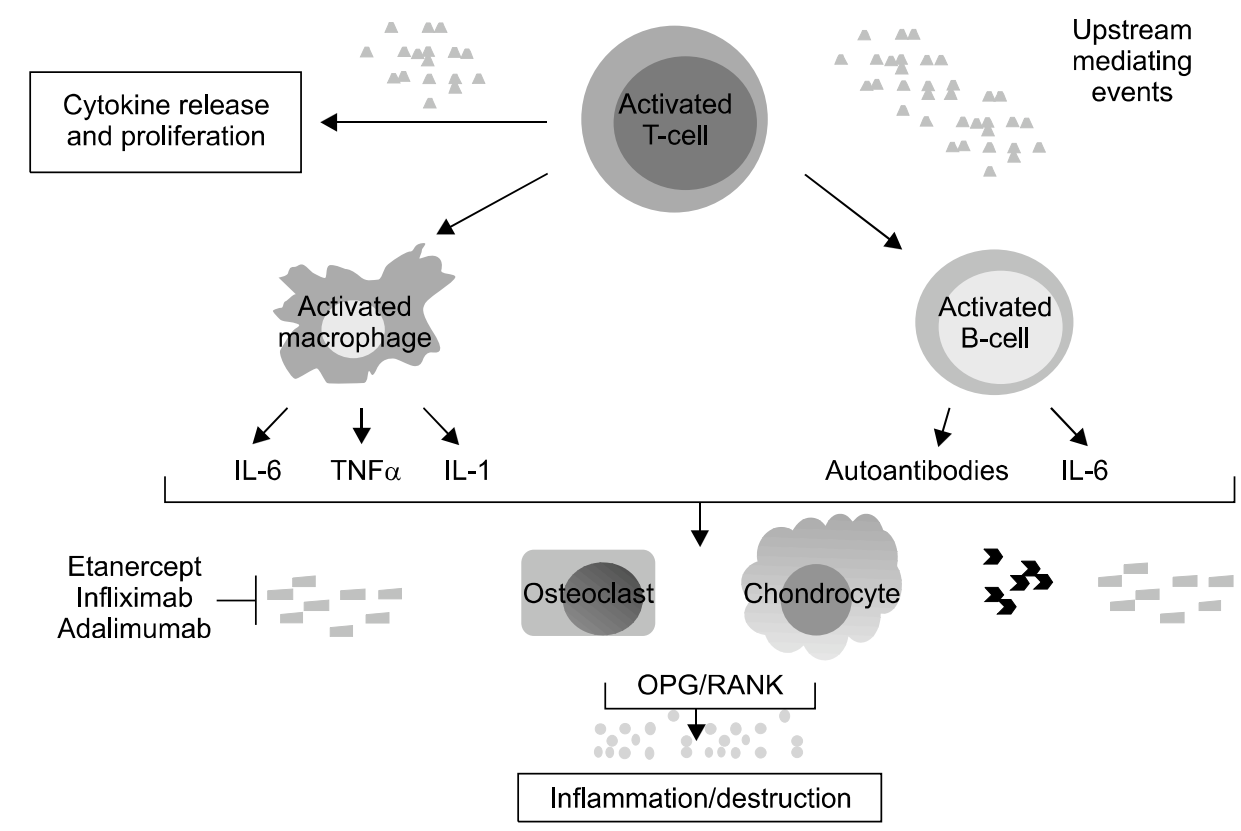

Figure 1. Pathogenesis of rheumatoid arthritis. 


\section{Fostamatinib}

Fostamatinib은 Syk inhibitor로서 현재 3개의 2상 연구 결 과가 발표되었다 (11-13). Syk은 B 림프구의 중요한 신호 전달 물질이자 $\mathrm{Fc} \gamma \mathrm{R}$ 의 신호전달에 관여하는 물질로서, 류마티스관절염에서 $\mathrm{B}$ 림프구 및 류마티스 인자의 역할을 고려할 때, 발병에 중요한 역할을 할 것으로 추정되는 신 호전달물질이다 (14) (Figure 2).

\section{효용성}

현재까지 발표된 3편의 2 상 연구 결과에 의하면 fostamati$\mathrm{nib}$ 은 MTX에 충분한 반응을 보이지 않은 환자에 대해서, $\mathrm{ACR} 20$ 달성율은 $32 \sim 72 \%$, ACR50 달성율은 $17 \sim 57 \%$, ACR70 달성율은 2 40\%로 대조군에 비해서 유의한 치료효 과를 보이는 것으로 확인되었다. 하지만, 대조군에서 ACR20 달성율도 $35 \sim 38 \%$ 로 높은 수준이어서 실제적인 임 상적 효용성은 3상 연구 결과를 확인해보아야 한다(Table 1).

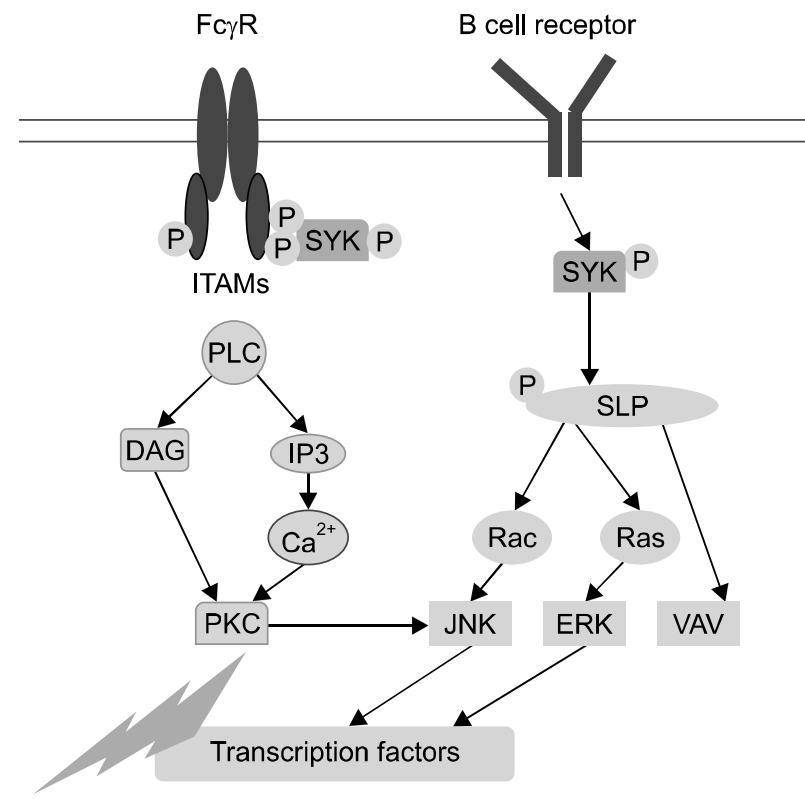

Figure 2. Signal transduction of Syk.
한편, 항TNF 제제에 충분한 반응을 보이지 않는 환자를 대 상으로 한 연구에서는 ACR20, ACR50, ACR70 달성율이 각 각 $38 \%, 33 \%, 9 \%$ 로 대조군과 비교해서 유의한 치료효과를 보여주지 못했다 (13). Fostamatinib이 삶의 질에 미치는 영향 에 대해서는 최근 보고되었으며 fostamatinib $100 \mathrm{mg}$ bid군의 경우, 환자가 평가한 질병활성도 및 통증 정도, fatigue 부분 에서 대조군에 비해 유의하게 효용성이 있었다 (15).

\section{부작용}

2상 연구결과에 의하면, fostamatinib의 부작용은 경미한 것 으로 보고되었다. 가장 흔한 부작용은 설사로 $11.8 \sim 19.1 \%$ 의 환자에서 발생했으며, 그 외에 고혈압, 오심, 백혈구감소, 두통, 복통과 같은 증상들이 보고되었다. 이 외에도 일부 환 자에서 감염에 의한 중대 합병증이 발생하였다(Table 2).

\section{현재 진행중인 연구들}

Fostamatinib은 현재 3상연구가 활발히 진행 중이다. MTX 에 충분히 반응을 보이지 않는 환자를 대상으로 하는 연구 (OSKIRA-1), 류마티스질병조절제에 충분한 반응을 보이 지 않는 환자를 대상으로 하는 연구(OSKIRA-2), 항TNF 제 제에 반응을 보이지 않는 환자를 대상으로 하는 연구 (OSKIRA-3)가 진행중이며, 이들 연구에 대한 장기간 효용 성과 부작용을 확인하는 연구도 진행 중이다.

\section{Tofacitinib}

Tofacitinib은 Janus activated kinase (JAK) 분자를 선택적으

Table 2. Common adverse effects of fostamatinib

\begin{tabular}{lc}
\hline \hline \multicolumn{1}{c}{ Adverse events } & Incidence \\
\hline Diarrhea & $12 \sim 45.0 \%$ \\
Headache & $5.9 \sim 13.0 \%$ \\
Hypertension & $+5 \mathrm{mmHg}$ \\
Elevation of AST/ALT & $3.0 \sim 9.0 \%$ \\
Leukopenia & $2 \sim 14 \%$ \\
\hline
\end{tabular}

Others: infection, malignancy

Table 1. Clinical trials of fostamtinib

\begin{tabular}{|c|c|c|c|c|c|c|c|}
\hline Patients & Duration (Month) & Treatment arms & Numbers & ACR20 (\%) & ACR50 (\%) & ACR70 (\%) & References \\
\hline \multirow[t]{4}{*}{ MTX-IR (2008) } & \multirow[t]{4}{*}{12} & Placebo & 47 & 38 & 19 & 4 & \multirow[t]{4}{*}{11} \\
\hline & & $50 \mathrm{mg}$ bid & 46 & 32 & 17 & 2 & \\
\hline & & $100 \mathrm{mg}$ bid & 49 & 65 & 49 & 33 & \\
\hline & & $150 \mathrm{mg}$ bid & 47 & 72 & 57 & 40 & \\
\hline \multirow[t]{3}{*}{ MTX-IR (2010) } & \multirow[t]{3}{*}{24} & Placebo & 153 & 35 & 19 & 10 & \multirow[t]{3}{*}{12} \\
\hline & & $150 \mathrm{mg}$ bid & 152 & 57 & 32 & 14 & \\
\hline & & $100 \mathrm{mg}$ bid & 152 & 67 & 43 & 28 & \\
\hline \multirow[t]{2}{*}{ TNF-IR (2010) } & \multirow[t]{2}{*}{12} & Placebo & 73 & 37 & 12 & 5 & \multirow[t]{2}{*}{13} \\
\hline & & $100 \mathrm{mg}$ bid & 146 & 38 & 33 & 9 & \\
\hline
\end{tabular}

IR, incomplete response 
로 차단하는 경구용 소분자억제제(CP-690,550)로서, tasocitinib으로 잠시 명명되었다가 최종적으로 tofacitinib으로 이름이 확정된 약제이다. JAK 분자는 JAK-1, JAK-2, JAK-3, TYK-2 를 포함한다. JAK 분자는 염증성 사이토카 인의 세포 내 수용체에 위치하며, 염증성 사이토카인이 수 용체와 결합하면, 인산화된 후 STAT 분자와 결합해서 염 증성 사이토카인의 시그날을 세포 내로 전달한다. Tofacitinib은 JAK 분자 모두를 차단하나 특히 JAK-1과 JAK-3를 차단한다(Figure 3). JAK-1은 IL-6와 interferon- $\gamma$ 의 신호전 달에 관여하며, JAK-3는 $\gamma$ 사슬을 공통적으로 갖는 염증 성 사이토카인(IL-2, IL-4, IL-7, IL-9, IL15, IL-21)의 신호전 달을 주로 차단한다. Tofacitinib은 현존하는 소분자억제제 중 가장 많은 임상연구가 현재 진행되어서 곧 임상에 출시 될 것으로 예상되는 약제이다 (16).

\section{임상 연구들}

Tofacitinib은 현재 2상 연구들의 결과들이 발표되었고, 3 상 연구결과들의 일부가 발표된 상태이다. Tofacitinib의 2 상 연구로는 tofacitinib 단독과 tofacitinib과 MTX를 병용한 연구가 발표되었다 $(17,18)$. Tofacitinib을 MTX와 병용한 제 2상 연구에서는 tofacitinib $1 \mathrm{mg} \mathrm{qd}, 1 \mathrm{mg}$ bid, $2 \mathrm{mg}$ bid, $5 \mathrm{mg}$ bid, $10 \mathrm{mg}$ bid, $15 \mathrm{mg}$ bid를 12주간 투여한 후 대조군에 비해서 효용성과 부작용을 검증한 결과, ACR20 달성율은 tofacitinib $3 \mathrm{mg}$ bid 이상을 투여한 경우 50.7 58.1\%로 대 조군의 $33.3 \%$ 에 비해서 유의하게 높았다 (18). Tofacitinib 을 단독으로 투여한 제2상 연구에서는 tofacitinib을 $1 \mathrm{mg}$ bid, $3 \mathrm{mg}$ bid, $5 \mathrm{mg}$ bid, $10 \mathrm{mg}$ bid, $15 \mathrm{mg}$ bid를 12주간 투여하고, adalimumab $40 \mathrm{mg} \mathrm{q} 2$ weeks를 투여한 군 및 대 조군과 효용성과 안전성을 검증했다. 이 연구 결과에 의하 면, tofacitinib군의 ACR $20 \%$ 달성률은 $39.2 \%$ (3 $\mathrm{mg} \mathrm{bid),}$ $59.2 \%$ (5 mg bid), 70.5\% (10 mg bid), 71.9\% (15 mg bid)로 adalimumab군의 $35.9 \%$, 대조군의 $22.0 \%$ 에 비해서 유의하 게 높았다 (17).

Tofacitinib의 3상 연구로는 류마티스질병조절제에 충분 한 반응을 보이지 않은 환자를 대상으로 tofacitinib의 단독 투여 효과를 분석한 ORAL-Solo (19), 류마티스 질병조절 제와의 병용투여효과를 분석한 ORAL-Sync연구 (20), MTX에 불충분한 반응을 보인 환자를 대상으로 MTX와의 병용투여 효과 및 X선 검사의 변화를 분석한 ORAL-Scan (21), adalimumab과의 치료효과를 비교한 ORAL-standard 연구 (22), 항TNF항체 치료에 실패한 환자를 대상으로 한 ORAL-Step 연구가 있고 (23), MTX에 노출이 되지 않은 환 자를 대상으로 tofacitinib과 MTX의 효과를 직접적으로 비 교하는 ORAL-Start 연구가 있다.

\section{효용성}

ORAL-Solo 연구는 3상 연구 중에서 유일하게 tofacitinib 단독 투여의 효과를 비교한 연구로서, 대조군에서 ACR20 달성율이 $27 \%$ 에 그친데 반해서 tofacitinib군에서는 60 $66 \%$ 의 치료효과를 보였다. HAQ-DI 에 있어서도, 대조군 에서의 개선 정도는 0.22 이하였는데 반해서, tofacitinib 군 에서는 0.50 0.55 호전되었다 (19). Oral-Sync 연구에서는 DMARD와 병용시 치료효과를 비교했는데, DMARD만 투 여된 대조군에서 ACR20 달성율이 $31.2 \%$ 이었는데 반해서 tofacitinib 군에서는 $52.7 \sim 58.3 \%$ 의 효과를 보여서 대조군 에 비해서 유의한 치료효과를 보였다. HAQ-DI 역시 대조 군에서 개선 정도가 0.22 이하였는데 반해서 치료군에서 는 $0.45 \sim 0.54$ 개선되었다 (20). 항TNF제제 중 adalimumab 과 tofacitinib 간의 효용성을 비교한 Oral-Standard 연구에 서는 tofacitinib과 adalimumab 모두 대조군에 비해서 유의 한 치료효과를 보였으며, 특히 ACR20 달성율이 tofacitinib 에서 52 54\%, adalimumab에서 $47 \%$ 로 tofacitinib은 adali-
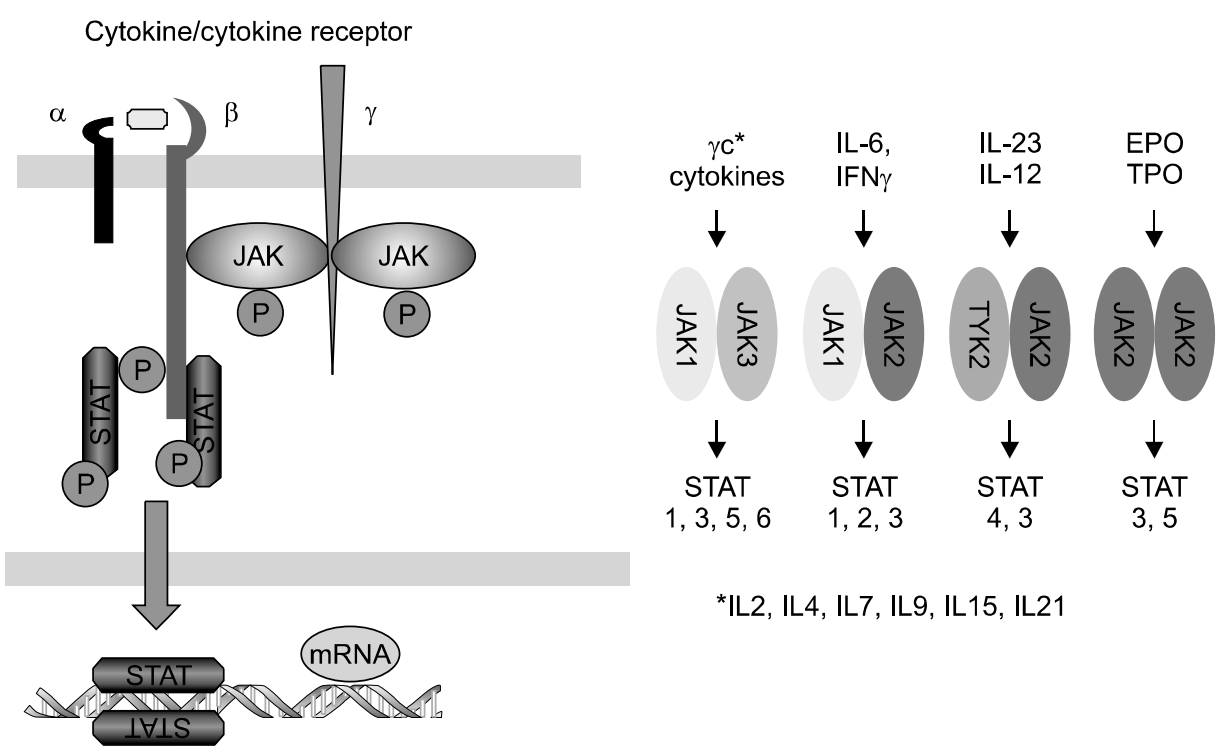

${ }^{*}$ IL2, IL4, IL7, IL9, IL15, IL21

Figure 3. Janus activated kinase inhibitors. 
Table 3. Clinical trials using tofacitinib

\begin{tabular}{|c|c|c|c|c|c|c|c|}
\hline Patients & Duration (Months) & Treatment arms & Numbers & ACR20 (\%) & ACR50 (\%) & ACR70 (\%) & References \\
\hline \multirow[t]{3}{*}{ DMARD IR } & \multirow[t]{3}{*}{6} & Placebo & 122 & 27 & 13 & 6 & \multirow[t]{3}{*}{19} \\
\hline & & $5 \mathrm{mg}$ bid & 243 & 60 & 31 & 15 & \\
\hline & & $10 \mathrm{mg}$ bid & 245 & 66 & 37 & 20 & \\
\hline \multirow[t]{3}{*}{ DMARD-IR } & \multirow[t]{3}{*}{6} & Placebo+DMARD & 157 & 31.2 & 12.7 & 3.2 & \multirow[t]{3}{*}{20} \\
\hline & & $5 \mathrm{mg}$ bid+DMARD & 311 & 52.7 & 33.8 & 13.2 & \\
\hline & & $10 \mathrm{mg} \mathrm{bid+DMARD}$ & 309 & 58.3 & 36.6 & 16.2 & \\
\hline \multirow[t]{4}{*}{ MTX-IR } & \multirow[t]{4}{*}{6} & Placebo+MTX & 59 & 28.3 & 12.3 & 1.9 & \multirow[t]{4}{*}{22} \\
\hline & & $5 \mathrm{mg} \mathrm{bid}+\mathrm{MTX}$ & 204 & 52 & 37 & 20 & \\
\hline & & $10 \mathrm{mg}$ bid+MTX & 201 & 53 & 35 & 22 & \\
\hline & & Adalimumab+MTX & 204 & 47 & 28 & 9 & \\
\hline \multirow[t]{3}{*}{ TNF-IR } & \multirow[t]{3}{*}{3} & Placebo & 132 & 24 & 8 & 2 & \multirow[t]{3}{*}{23} \\
\hline & & $5 \mathrm{mg}$ bid & 133 & 42 & 27 & 14 & \\
\hline & & $10 \mathrm{mg}$ bid & 134 & 48 & 28 & 11 & \\
\hline
\end{tabular}

The values are $51.5 \%$ and $54.9 \%$ respectively at 6 months. IR, incomplete response; DMARD, disease modifying anti-rheumatic drugs

mumab 과 유사하거나 그 이상의 치료효과를 보였다 (22). 항TNF 제제에 대해서 충분한 반응을 보이지 않는 환자를 대상으로 한 Oral-Step 연구에서는 ACR20 달성 율이 대조 군에서 $24 \%$ 에 불과한데 반해서, tofacitinib 군에서는 42 $48 \%$ 로 유의한 차이를 보였다. 3 개월째의 HAQ-DI는 대조 군에서의 개선 정도가 0.22 이하이었는데 반해서 tofacitinib군에서는 $0.43 \sim 0.46$ 이었다 (23). X선 검사를 이용해서 관절 파괴 정도를 측정한 ORAL-Scan 결과에 따르면, tofacitinib+MTX와 MTX군을 비교했을 때 6개월째 modified Sharp Score 의 변화가 tofacitinib $10 \mathrm{mg}$ bid군에서는 0.12 였 는데 비해서 대조군에는 0.47 로 유의한 차이가 있었다 (21). 결론적으로 tofacitinib은 제 2 상, 제 3 상 연구를 통해서 일관적으로 객관적 임상 지표의 개선, 주관적 임상지표의 개선 및 관절파괴에 대한 보호효과를 보였다(Table 3).

\section{안전성}

제 2상 연구결과에 의하면, tofacitinib의 부작용 프로파일 은 항TNF제제와 유사할 것으로 예측되고 있다. 중대한 부 작용(serious adverse event)는 tofacitinib군에서 $1.6 \sim 7.0 \%$ 에 서 발생한 데 비해서 adalimumab군에서는 1.9 9.1\%에서 발생했으며, 대조군에서는 $5.9 \%$ 에서 발생했다. 심각한 감 염증은 tofacitinib군에서 $5.9 \%$ 에서 발생한 데 비해서, adalimumab군에서는 $2.3 \%$, 대조군에서는 $2.9 \%$ 에서 발생했다. 검사상의 이상소견으로는 백혈구 감소증, 빈혈, 혈청 크레 아티닌의 상승, cholesterol의 상승이 관찰되었으나, 약제를 지속하면 안정되는 경향을 보였다 (17). 3상 연구와 장기연 장연구 결과에 의하면, 감염은 주로 비인두염, 상기도 감 염, 요로감염, 기관지염, 대상포진, 인플루엔자의 순서로 흔하게 발생했다. 일일 $5 \mathrm{mg}$ bid 군보다 $10 \mathrm{mg}$ bid군은 장 기 연장 연구 시 감염의 발생빈도가 높았다. 결핵을 포함 한 기회감염의 발생은 드문 것으로 보고되었다 $(24,25)$.
Table 4. Other small molecule inhibitors

\begin{tabular}{llrlc}
\hline \hline Medication & \multicolumn{1}{c}{ Target } & Phase & \multicolumn{1}{c}{ Effecacy } & References \\
\hline VX-509 & JAK3 & Phase 2 & Effective & 26 \\
SCIO-469 & P38MAPK & Phase 2 & No effect & 27 \\
VX-702 & P38MAPK & Phase 2 & No effect & 28 \\
LX3305 & S1P lyase & Phase 2 & No effect & 29 \\
CCX354-C & CCR1 & Phase 2 & Possible effect & 30 \\
\hline
\end{tabular}

\section{기타 소분자억제제}

JAK을 표적으로 한 치료제로는 VX-509 (JAK3) 등이 있 었으나 최근에 새로운 임상결과가 발표되지는 않았다 (26). 세포내 중요 신호전달 물질인 p38 MAP-kinase를 표 적으로 한 치료제로는 VX-702, SCIO-469 등이 임상 2상을 마쳤으나, 대조군에 비해서 임상적 효용성에서 유의한 차 이가 없어서 그 이후의 임상결과는 보고가 없는 상태이다 $(27,28)$. LX3305는 S1P lyase를 억제함으로써 림프구의 이 동을 억제하는 약제이나 임상 2상에서 뚜렷한 임상적 효 용성은 보이지 못했다 (29). CCR1 chemokine의 차단제인 $\mathrm{CCX} 354-\mathrm{C}$ 는 임상 제 2 상에서 전체 환자에서는 12 주째의 ACR20 달성률이 43 52\%로 대조군 39\%에 비해서 뚜렷한 차이를 보여주지 못했고, 일부 특정군의 환자에서만 효과 를 보였다(Table 4) (30).

\section{결 롤}

소분자억제제는 스테로이드제제, 비스테로이드성항염제, 류마티스질병조절제 및 생물학적 제제에 이어서 류마티스 관절염의 새로운 치료제로 자리매김할 가능성이 높은 약 제이다. 특히 소분자억제제는 경구 복용이 가능하고, 저가 로 대량생산이 가능한 점, 그리고 급속한 치료 효과는 기존 약제의 한계를 극복할 수 있는 중요한 특성이다. 다만 소분 자억제제도 면역 기능에 지대한 영향을 미치므로 안전성 에 대해서는 장기 연구 결과들을 확인해 보아야 한다. 


\section{참고문헌}

1. Lee DM, Weinblatt ME. Rheumatoid arthritis. Lancet 2001;358;903-11.

2. Moreland LW, Schiff MH, Baumgartner SW, Tindall EA, Fleischmann RM, Bulpitt KJ, et al. Etanercept therapy in rheumatoid arthritis. A randomized, controlled trial. Ann Intern Med 1999;130:478-86.

3. Lipsky PE, van der Heijde DM, St Clair EW, Furst DE, Breedveld FC, Kalden JR, et al; Anti-Tumor Necrosis Factor Trial in Rheumatoid Arthritis with Concomitant Therapy Study Group. Infliximab and methotrexate in the treatment of rheumatoid arthritis. Anti-Tumor Necrosis Factor Trial in Rheumatoid Arthritis with Concomitant Therapy Study Group. N Engl J Med 2000;343: 1594-602.

4. Weinblatt ME, Keystone EC, Furst DE, Moreland LW, Weisman MH, Birbara CA, et al. Adalimumab, a fully human anti-tumor necrosis factor alpha monoclonal antibody, for the treatment of rheumatoid arthritis in patients taking concomitant methotrexate: the ARMADA trial. Arthritis Rheum 2003;48:35-45.

5. Kay J, Matteson EL, Dasgupta B, Nash P, Durez P, Hall $\mathrm{S}$, et al. Golimumab in patients with active rheumatoid arthritis despite treatment with methotrexate: a randomized, double-blind, placebo-controlled, dose-ranging study. Arthritis Rheum 2008;58:964-75.

6. Keystone E, Heijde D, Mason D Jr, Landewé R, Vollenhoven RV, Combe B, et al. Certolizumab pegol plus methotrexate is significantly more effective than placebo plus methotrexate in active rheumatoid arthritis: findings of a fifty-two-week, phase III, multicenter, randomized, double-blind, placebo-controlled, parallel-group study. Arthritis Rheum 2008;58:3319-29.

7. Maini RN, Taylor PC, Szechinski J, Pavelka K, Bröll J, Balint G, et al; CHARISMA Study Group. Double-blind randomized controlled clinical trial of the interleukin- 6 receptor antagonist, tocilizumab, in European patients with rheumatoid arthritis who had an incomplete response to methotrexate. Arthritis Rheum 2006;54: 2817-29.

8. Edwards JC, Szczepanski L, Szechinski J, FilipowiczSosnowska A, Emery P, Close DR, et al. Efficacy of B-cell-targeted therapy with rituximab in patients with rheumatoid arthritis. N Engl J Med 2004;350:2572-81.

9. Genovese MC, Covarrubias A, Leon G, Mysler E, Keiserman M, Valente R, et al. Subcutaneous abatacept versus intravenous abatacept: a phase IIIb noninferiority study in patients with an inadequate response to methotrexate. Arthritis Rheum 2011;63:2854-64.

10. Tak PP, Kalden JR. Advances in rheumatology: new targeted therapeutics. Arthritis Res Ther 2011;13 Suppl 1:S5.

11. Weinblatt ME, Kavanaugh A, Burgos-Vargas R, Dikranian AH, Medrano-Ramirez G, Morales-Torres JL, et al. Treatment of rheumatoid arthritis with a Syk kinase inhibitor: a twelve-week, randomized, placebo-controlled trial. Arthritis Rheum 2008;58:3309-18.

12. Weinblatt ME, Kavanaugh A, Genovese MC, Musser TK, Grossbard EB, Magilavy DB. An oral spleen tyrosine kin- ase (Syk) inhibitor for rheumatoid arthritis. N Engl J Med 2010;363:1303-12.

13. Genovese MC, Kavanaugh A, Weinblatt ME, Peterfy C, DiCarlo J, White ML, et al. An oral Syk kinase inhibitor in the treatment of rheumatoid arthritis: a three-month randomized, placebo-controlled, phase II study in patients with active rheumatoid arthritis that did not respond to biologic agents. Arthritis Rheum 2011;63:337-45.

14. Bajpai M, Chopra P, Dastidar SG, Ray A. Spleen tyrosine kinase: a novel target for therapeutic intervention of rheumatoid arthritis. Expert Opin Investig Drugs 2008;17: 641-59.

15. Weinblatt ME, Kavanaugh A, Genovese MC, Jones DA, Musser TK, Grossbard EB, et al. Effects of the Oral SYKInhibitor, fostamatinib (R788), on health-related quality of life in a phase II study of active rheumatoid arthritis. Arthritis Rheum 2011;63:S158.

16. Riese RJ, Krishnaswami S, Kremer J. Inhibition of JAK kinases in patients withrheumatoid arthritis: scientific rationale and clinical outcomes. Best Pract Res Clin Rheumatol 2010;24:513-26.

17. Fleischmann R, Cutolo M, Genovese MC, Lee EB, Kanik $\mathrm{KS}$, Sadis $\mathrm{S}$, et al. Phase IIb dose-ranging study of the oral JAK inhibitor tofacitinib (CP-690,550) or adalimumab monotherapy versus placebo in patients with active rheumatoid arthritis with an inadequate response to disease- modifying antirheumatic drugs. Arthritis Rheum 2012;64: 617-29.

18. Kremer JM, Cohen S, Wilkinson BE, Connell CA, French $\mathrm{JL}$, Gomez-Reino J, et al. A phase IIb dose-ranging study of the oral JAK inhibitor tofacitinib (CP-690,550) versus placebo in combination with background methotrexate in patients with active rheumatoid arthritis and an inadequate response to methotrexate alone. Arthritis Rheum 2012;64: 970-81.

19. Fleishmann R, Kremer J, Cush J, et al. Phase 3 study of Oral JAK inhibitor Tasocitinib (CP-690-550) Monotherapy in patients with active rheumatoid arthritis. Arthritis Rheum 2010;62:LB8

20. Kremer J, Li ZG, Hall S, et al. Tofacitinib (CP-690,550), an oral JAK inhibitor, in combination with traditional DMARDs: phase 3 study in patients with active rheumatoid arthritis with inadequate response to DMARDs (abstract). Ann Rheum Dis 2011;70:170.

21. van der Heijde D, Tanaka Y, Fleischmann R, Keystone EC, Kremer JM, Zerbini CAF, et al. Tofacitinib (CP-690,550), an oral Janus kinase inhibitor, in combination with methotrexate reduced the progression of structural damage in patients with rheumatoid arthritis: a 24-month phase 3 study. Arthritis Rheum 2011;63(10 Suppl):Abstract 2592.

22. Van Vollenhoven R, Fleischmann R, Cohen S, et al. Tofacitinib (CP-690,550), an oral Janus Kinase inhibitor, or adalimumab versus placebo in patients with rheumatoid arthritis on background methotrexate: a phase 3 study. Arthritis Rheum 2011;63(10 Suppl):Abstract 408.

23. Burmester G, Blanco R, Charles-Schoeman C, Wollen- 
haupt J, Zerbini C, Benda B, et al. Tofacitinib (CP690,550 ), an oral Janus kinase inhibitor, in combination with methotrexate, in patients with active rheumatoid arthritis with an inadequate response to tumor necrosis factor-inhibitor: a 6-month phase 3 study. Arthritis Rheum 2011;63(10 Suppl):Abstract 718.

24. Wollenhaupt J, Silverfield JC, Lee EB et al. Tofacitinib (CP-690,550), an oral Janus kinase inhibitor, in the treatment of rheumatoid arthritis: open-label, long-term extension studies up to 36 months. Arthritis Rheum 2011; 63(10 Suppl):Abstract 407.

25. Cohen S, Radominski S, Asavartanabodee $P$, et al. Tofacitinib (CP-690,550), an oral Janus kinase inhibitor: analysis of infections and all-cause mortality across phase 3 and long-term extension studies in patients with rheumatoid arthritis. Arthritis Rheum 2011;63(10 Suppl): Abstract 409.

26. Fleischmann R. Novel small-molecular therapeutics for rheumatoid arthritis. Curr Opin Rheumatol 2012;24: $335-41$.

27. Genovese MC, Cohen SB, Wofsy D, Weinblatt ME,
Firestein GS, Brahn E, et al. A 24-week, randomized, double-blind, placebo-controlled, parallel group study of the efficacy of oral SCIO-469, a p38 mitogen-activated protein kinase inhibitor, in patients with active rheumatoid arthritis. J Rheumatol 2011;38:846-54.

28. Damjanov N, Kauffman RS, Spencer-Green GT. Efficacy, pharmacodynamics, and safety of VX-702, a novel p38 MAPK inhibitor, in rheumatoid arthritis: results of two randomized, double-blind, placebo-controlled clinical studies. Arthritis Rheum 2009;60:1232-41.

29. Fleischmann R, Poiley J, Stoilov R, et al. The oral S1P lyase inhibitor LX3305 (LX2931) demonstrates favorable safety and potential clinical benefit at 12 weeks in a phase 2 proof-of-concept trial in pateints with active rheumatoid arthritis on stable methotrexate therapy. Arthritis Rheum 2011;63(10 Suppl):Abstract 2593.

30. Tak PP, Balanescu A, Tseluyko V, Bojin S, Drescher E, Dairaghi D, et al. Chemokine receptor CCR1 antagonist CCX354-C treatment for rheumatoid arthritis: CARAT-2, a randomised, placebo controlled clinical trial. Ann Rheum Dis 2012 [Epub ahead of print]. 